\title{
Associação entre a infecção por Chikungunya Vírus e o desenvolvimento de formas graves da doença: uma revisão sistemática
}

\author{
Association between a Chikungunya infection virus and the development of serious forms \\ of the disease: a systematic review
}

\begin{abstract}
Asociación entre la infección por Chikungunya y el desarrollo de formas graves de la enfermedad: una revisión sistemática
\end{abstract}

Ana Carolina Aguiar Cardoso ${ }^{1 *}$, Vitor Monte de Castro Alencar ${ }^{1}$, Lucas Carvalho Soares ${ }^{1}$, Talita Fonsêca Terto ${ }^{1}$, Wanessa Landim Porto ${ }^{1}$, Ana Rachel Oliveira de Andrade ${ }^{1}$, Antonio de Pádua Rocha Nóbrega Neto ${ }^{1}$, Antonione Santos Bezerra Pinto ${ }^{1}$, José Lopes Pereira Júnior ${ }^{1}$, Priscila Favoritto Lopes ${ }^{1}$, Thiago de Souza Lopes Araújo ${ }^{1}$, Vanessa Poleana Silva ${ }^{2}$, Tereza Cristina de Carvalho Souza Garcês'.

\section{RESUMO}

Objetivo: Realizar uma revisão sistemática da literatura sobre a associação entre a infecção por Chikungunya virus (CHIKV) com o desenvolvimento de formas graves da doença. Métodos: Trata-se de uma revisão sistemática descritiva desenvolvida por meio da seleção de artigos nas bases de dados Scielo e PubMed, entre os anos 2014 a 2017, nas línguas portuguesa, espanhola e inglesa. Utilizando os descritores: Chikungunya; Chikungunya fever; Formas graves; Arboviroses; Formas crônicas; Combate ao Aedes. Resultados: Observou-se com base nas pesquisas, o grande potencial da CHIKV no desenvolvimento de formas graves e sua contribuição em sequelas debilitantes nos pacientes. Conclusão: Os agravos da febre da Chikungunya têm sido responsáveis pelos acometimentos de vários órgãos do organismo humano. Além disso, tem o potencial de descompensar comorbidades pré-existentes nos pacientes. Dessa forma, o vírus é capaz de desenvolver quadros de sintomatologia severa e sequelas debilitantes. Devido a isso, os estudos a respeito desses agravos e complicações, mesmo que ainda insuficientes e inconclusivos, são de extrema importância para o manejo desta infecção.

Palavras-chave: Arboviroses, Febre Chikungunya, Formas graves.

\begin{abstract}
Objective: To perform a systematic review of the literature on the association between Chikungunya virus infection (CHIKV) and the development of severe forms of the disease. Methods: This is a descriptive systematic review developed through the selection of articles in the Scielo and PubMed databases, between the years 2014 and 2017, in the Portuguese, Spanish and English languages. Using the descriptors: Chikungunya; Chikungunya fever; Severe forms; Arboviroses; Chronic forms; Fight against aedes. Results: The great potential of CHIKV in the development of severe forms and its contribution to debilitating sequelae in patients was observed based on the research. Conclusion: Chikungunya fever aggravations have been responsible for the involvement of various organs of the human body. In addition, it has the potential to decompensate pre-existing comorbidities in patients. In this way, the virus is capable of developing severe symptoms and debilitating sequelae. Due to this, studies regarding these agravos and complications, even if still insufficient and inconclusive, are extremely important for the management of this infection.
\end{abstract}

Key words: Arboviroses, Chikungunya fever, Severe forms.

\footnotetext{
${ }^{1}$ Instituto de Educação Superior do Vale do Parnaíba (FAHESP-IESVAP), Parnaíba-PI.

*E-mail: carolcardosoaguiar@gmail.com

2Universidade Federal do Piauí, Parnaíba, Piauí.
} 


\section{RESUMEN}

Objetivo: Realizar una revisión sistemática de la literatura sobre la asociación entre la infección por Chikungunya virus (CHIKV) con el desarrollo de formas graves de la enfermedad. Métodos: Se trata de una revisión sistemática descriptiva desarrollado a través de la selección de artículos en SciELO y base de datos PubMed entre los años 2014 a 2017, en el portugués, español e inglés. Utilizando los descriptores: Chikungunya; Chikungunya fever; Formas graves; arbovirus; Formas crónicas; Combate al Aedes. Resultados: Se observó con base en las investigaciones el gran potencial de CHIKV en el desarrollo de formas graves y su contribución en secuelas debilitantes en los pacientes. Conclusión: Los agravios de la fiebre de la Chikungunya han sido responsables por los acometimentos de varios órganos del organismo humano. Además, tiene el potencial de descompensar las comorbilidades preexistentes en los pacientes. De esta forma, el virus es capaz de desarrollar cuadros de sintomatología severa y secuelas debilitantes. Debido a esto, los estudios acerca de estos agravios y complicaciones, aunque aún insuficientes e inconclusivos, son de extrema importancia para el manejo de esta infección.

Palabras clave: Arbovirus, Fiebre Chikungunya, Formas graves.

\section{INTRODUÇÃO}

Os arbovírus são vírus transmitidos por vetores artrópodes hematófagos (LOPES N, et al. 2014). A transmissão ocorre através da picada de fêmeas do mosquito do gênero Aedes, em especial o Aedes aegypti e Aedes albopictus (HONÓRIO NA, et al. 2015). Os vírus de maior circulação no Brasil são o Dengue Virus (DENV), Chikungunya Virus (CHIKV), e Zika Virus (ZIKV) (DONALISIO MR, et al. 2017). Dentre eles, destacase o CHIKV, que pertence à família Togaviridae e gênero Alphavirus (CUNHA RV e TRINTA KS, 2015).

Este foi descrito pela primeira vez na região da Tanzânia, durante um surto ocorrido no ano de 1950 e a princípio acreditava-se ser causado pelo DENV (DONALISIO MR e FREITAS ARR, 2015). Apesar disso, foi somente no ano de 2014, após pequenos e grandes surtos acometidos em outras regiões do mundo, que foram relatados os primeiros casos autóctones no Brasil, onde o fatores como o favorecimento do clima tropical, o aumento do fluxo de pessoas entre países e a cocirculação do CHIKV com outros arbovírus foram cruciais para a disseminação da doença para torná-la emergente (MARQUES CDL, et al. 2017).

A infecção atinge principalmente as articulações e pode debilitar milhares de brasileiros, causando sintomas semelhantes aos de outras arboviroses e, também, considerável impacto econômico e social ao Brasil. Desses sintomas, a artralgia simétrica foi considerado o mais característico da doença, com potencial de perdurar durante meses até anos (HONÓRIO NA, et al. 2015).

Diante desse cenário alarmante, o presente estudo tem como objetivo analisar através de uma revisão sistemática, a associação entra a infecção por CHIKV com o desenvolvimento de formas graves, quais órgãos/sistemas são mais acometidos e quais fatores agem a favor do desenvolvimento destas formas graves. Para, dessa forma contribuir para o manejo dos pacientes que forem acometidos por complicações desta infecção. Consequentemente, colaborando para o alcance de melhores prognósticos.

\section{MÉTODOS}

Trata-se de uma revisão sistemática de literatura onde os artigos foram selecionados utilizando um estudo secundário, onde procura-se, na literatura já existente, associar diferentes pesquisas realizadas em torno de um tema em comum, buscando, entre eles, informações com o intuito de se avaliar criticamente a qualidade da sua metodologia, informações e evidências. A busca foi realizada nas bases de dados Scientific Electronic Library Online (Scielo), e Pubmed (Public Medline) com artigos do tipo relato de caso, nos anos de 2014 a 2019, utilizando os descritores na língua inglesa: Chikungunya fever; Severe forms; Chronic forms; e portuguesa: Chikungunya; Formas graves; Arboviroses; Formas crônicas.

Foram utilizados como critérios de inclusão artigos na língua portuguesa, espanhola e inglesa, com o tema principal o Chikungunya virus e o desenvolvimento de formas graves em humanos. Os artigos que se enquadram nos critérios de exclusão são os do tipo revisão sistemática. 
Para a extração de dados, foram primeiramente avaliados os títulos dos artigos, com o intuito de se constatar qual objetivo de cada um deles. Após isso, os resumos dos estudos remanescentes foram analisados para se averiguar seus objetivos e metodologia. Por fim, o restante dos artigos foram apurados nos conformes dos critérios de inclusão e exclusão através de toda sua leitura e análise integralmente (Figura 1).

Figura 1 - Método de seleção de artigos.

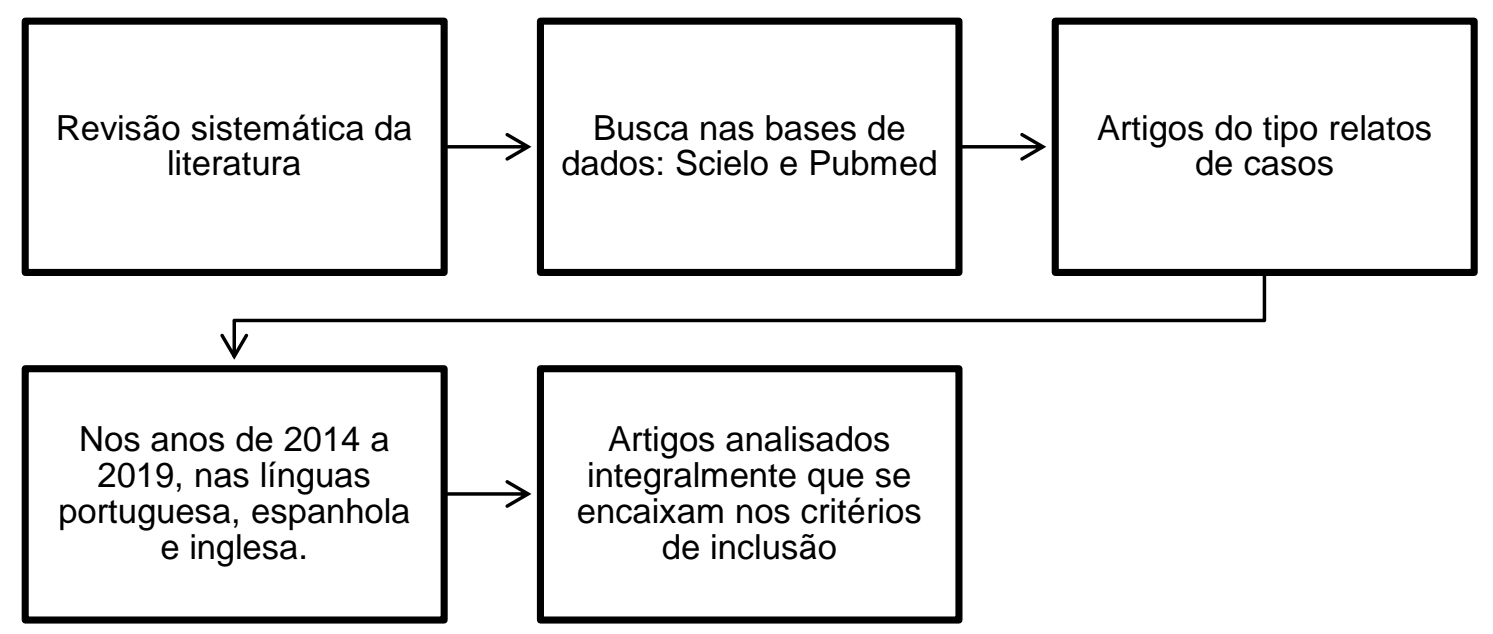

Fonte: CARDOSO ACA, ALENCAR VMC, SOARES LC, et al., 2019.

\section{RESULTADOS E DISCUSSÃO}

Foram encontrados 41 artigos compatíveis com o tema do estudo, os quais estavam disponíveis nas bases de dados Scielo e Pubmed. Destes artigos, apenas 18 foram utilizados e 25 foram excluídos (Figura 2).

Procurou-se listar, em cada um deles, autores, o artigo, as manifestações clínicas e a conduta terapêutica. Observou-se que esta infecção possui a capacidade de acometer grande parte dos órgãos e sistemas do ser humano. E, relatos recém-publicados sobre os agravos desta infecção trazem consigo novos locais de acometimentos antes não associados a doença. Dentre as manifestações mais comuns, é notável o acometimento prevalente do sistema nervoso. Apesar de possuir causas não esclarecidas na literatura, 0 acometimento nervoso pela infecção do CHIKV tem sido alvo de inúmeras pesquisas com o intuito de esclarecer o motivo pelo qual o mesmo vírus que pode desenvolver uma infecção assintomática pode, também, desenvolver doenças neurológicas.

De acordo com estudos recentes, as células cerebrais, como os astrócitos e oligodendrócitos são altamente sensíveis à infecção por CHIKV. Diante disso, ao serem infectadas pelos vírus, essas células liberam consideráveis níveis de citocinas e quimiocinas. Consequentemente, ocorre uma alteração do número e da distribuição de sinápses formadas por cada astrócito. Logo, comprovariam o fato de que a infecção pelo CHIKV induz a ativação imune morfométrica e inata de astrócitos (PINHEIRO TJ, et al. 2016)

Em pacientes com neuropatia secundária, quatro citocinas: Fator de Necrose Tumoral alfa (TNF- $\alpha$ ), Interferon alfa (IFN- $\alpha$ ) e monoquina induzida por Interferon gama (IFN- - ), foram encontradas em valores consideravelmente maiores, contrariando os valores encontrados em paciente com infecção pelo CHIKV não complicada (MEHTA R, et al. 2018). 
Figura 2 - Processo de seleção dos dados.

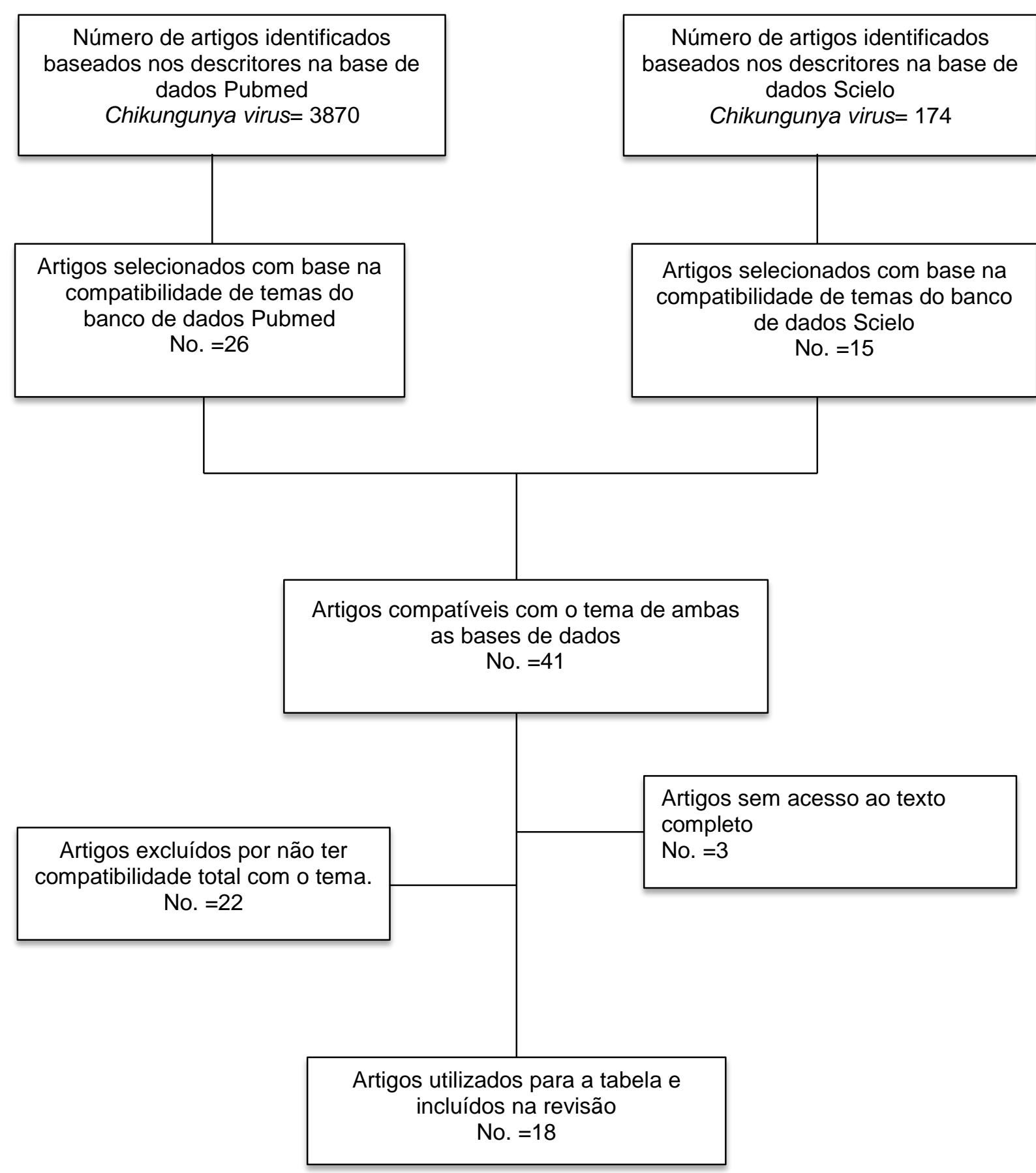

Fonte: CARDOSO ACA, ALENCAR VMC, SOARES LC, et al., 2019.

Outra forma menos prevalente, são os acometimentos oculares causados pela infecção do CHIKV que, assim como o neurológico, necessitam de mais estudos detalhados para total compreensão do mecanismo fisiopatológico. A concomitância dos acometimentos oculares e sistêmicos sugerem a possível envoltura viral direta, como conjuntivite, uveíte anterior, retinite viral e neurite óptica. Envoltura essa, que se confirma com a detecção de antígenos do CHIKV em ceratócitos do estroma corneano e esclera, em fibroblastos do estroma da íris e em fibroblastos de corpos ciliares, sugerindo envolvimento ocular direto (MAHENDRADAS P, et al. 2013). 
Quadro 1 - Desenvolvimento de formas graves associados a infecção por CHIKV.

\begin{tabular}{|c|c|c|c|}
\hline Autores & Artigo & Manifestações clínicas & Conduta terapêutica \\
\hline $\begin{array}{l}\text { BANK AM, et al., } \\
2015 .\end{array}$ & $\begin{array}{l}\text { Myeloradiculopathy associated } \\
\text { with chikungunya virus infection }\end{array}$ & $\begin{array}{l}\text { Febre, erupção cutânea e diarréia fraqueza e } \\
\text { diminuição da sensação abaixo do umbigo. } \\
\text { Posteriormente desenvolveu flexão do quadril } \\
\text { esquerdo, extensão do joelho e } \\
\text { fraqueza na flexão do joelho, com mínimo movimento } \\
\text { contra a gravidade. A sensação foi diminuída em todas } \\
\text { as modalidades até nivel de T12. }\end{array}$ & $\begin{array}{l}\text { Fez uso de metilprednisolona } \\
\text { intravenosa. }\end{array}$ \\
\hline $\begin{array}{l}\text { ESTOFOLETE } \\
\text { CF, et al., } 2016 .\end{array}$ & $\begin{array}{l}\text { Mayaro fever in an HIV-infected } \\
\text { patient suspected of having } \\
\text { Chikungunya fever }\end{array}$ & Mialgia, artralgia, febre e dor de cabeça holocraniana. & $\begin{array}{l}\text { O paciente foi hospitalizado para } \\
\text { tratamento de } \\
\text { neurossífilis assintomática; ele recebeu } \\
\text { penicilina parenteral } \\
\text { por } 10 \text { dias. O paciente experimentou } \\
\text { alívio espontâneo da } \\
\text { mialgia e artralgia, recebendo alta sem } \\
\text { sintomas. } \\
\text { Ele permanece sob acompanhamento } \\
\text { ambulatorial. }\end{array}$ \\
\hline $\begin{array}{l}\text { LIN J, et al., } \\
\text { 2016. }\end{array}$ & 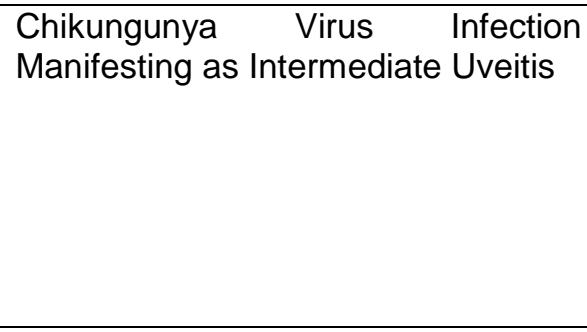 & $\begin{array}{l}\text { Visão embaçada no olho direito, febre alta e dor nas } \\
\text { extremidades inferiores. }\end{array}$ & $\begin{array}{l}\text { Iniciou o tratamento com } 60 \mathrm{mg} \text { de } \\
\text { prednisona oral, além de esteróides } \\
\text { tópicos e } \\
\text { cicloplegia. O paciente também foi } \\
\text { iniciado profilaticamente com } \\
\text { isoniazida e vitamina B6 para prevenir } \\
\text { reativação de possível tuberculose } \\
\text { latente. }\end{array}$ \\
\hline $\begin{array}{l}\text { MARTINS HA, et } \\
\text { al., } 2016 .\end{array}$ & $\begin{array}{l}\text { Chikungunya and Myositis: A Case } \\
\text { Report in Brazil }\end{array}$ & $\begin{array}{l}\text { Confusão mental e agressividade, febre, artralgia e } \\
\text { fraqueza em membros inferiores. }\end{array}$ & $\begin{array}{l}\text { Medicação antipsicótica (risperidona } 2 \\
\text { mg) e cuidados de suporte. }\end{array}$ \\
\hline $\begin{array}{l}\text { BENZEKRI R, et } \\
\text { al., } 2016 .\end{array}$ & $\begin{array}{ll}\text { Third Cranial Nerve } & \text { Palsy in the } \\
\text { Setting of } & \text { Chikungunya } \\
\text { Virus Infection } & \end{array}$ & $\begin{array}{l}\text { Diplopia binocular horizontal e pálpebra caída } \\
\text { esquerda, febre, dores de cabeça e poliartralgia (ambos } \\
\text { os pulsos e tornozelos) }\end{array}$ & $\begin{array}{l}\text { O paciente foi iniciado com aspirina. O } \\
\text { tratamento foi sintomático e incluiu fita } \\
\text { adesiva sobre a lente esquerda de seus } \\
\text { óculos para suprimir a diplopia no olhar } \\
\text { primário e manter uma boa campo } \\
\text { visual periférico. }\end{array}$ \\
\hline
\end{tabular}




\begin{tabular}{|c|c|c|c|}
\hline $\begin{array}{l}\text { PEREIRA LP, et } \\
\text { al., } 2017 .\end{array}$ & $\begin{array}{l}\text { Encephalitis associated with the } \\
\text { chikungunya epidemic outbreak in } \\
\text { Brazil: report of } 2 \text { cases with } \\
\text { neuroimaging findings }\end{array}$ & $\begin{array}{l}\text { Caso 1: Febre, poliartralgia, erupção cutânea difusa, } \\
\text { adinamia, conjuntivite, tosse seca e desorientação no } \\
\text { tempo e espaço. Caso 2: Febre maculopapular } \\
\text { erupção, confusão e nível flutuante } \\
\text { de consciência. Desenvolveu fraqueza progressiva dos } \\
\text { membros inferiores potência inicial de grau } 3 \text { nos } \\
\text { membros inferiores, progredindo rapidamente para } \\
\text { grau } 0 \text { após } 5 \text { dias) e arreflexia difusa. }\end{array}$ & $\begin{array}{l}\text { Caso 1: Corticosteróide intravenoso } \\
\text { (dexametasona, } 40 \mathrm{mg} \text {, } \\
\text { a cada } 6 \mathrm{~h} \text { ) Caso } 2 \text { : } \\
\text { imunoglobulina intravenosa }(400 \mathrm{mg} / \\
\mathrm{kg} \text { / dia) por } 5 \text { dias. }\end{array}$ \\
\hline $\begin{array}{l}\text { LUCENA-SILVA } \\
\mathrm{N} \text {, et al., } 2017 .\end{array}$ & $\begin{array}{l}\text { Encephalitis associated with } \\
\text { inappropriate antidiuretic hormone } \\
\text { secretion due to chikungunya } \\
\text { infection in Recife, State of } \\
\text { Pernambuco, Brazil }\end{array}$ & $\begin{array}{l}\text { Astenia, edema, eritema, } \\
\text { artralgia envolvendo os punhos, joelhos e tornozelos e } \\
\text { bolhas } \\
\text { nos pulsos e palato. }\end{array}$ & $\begin{array}{l}\text { Sete meses de reabilitação com um } \\
\text { terapeuta de linguagem, fisioterapeuta } \\
\text { e psicólogo. }\end{array}$ \\
\hline $\begin{array}{l}\text { SCOTT SSO, et } \\
\text { al., } 2017 .\end{array}$ & $\begin{array}{l}\text { Immunoglobulin-responsive } \\
\text { chikungunya encephalitis: two case } \\
\text { reports }\end{array}$ & $\begin{array}{l}\text { Caso 1: Febre, erupção maculopapular e artralgia } \\
\text { grave. Confusão e flutuação do nível de consciência. } \\
\text { Sonolento e desorientado no espaço e no tempo. } \\
\text { Paraparesia com arreflexia difusa. } \\
\text { Caso 2: Febre com calafrios, artralgias } \\
\text { letargia e confusão com desorientação no tempo e no } \\
\text { espaço. O estado neurológico evoluiu com piora do } \\
\text { nível de consciência. }\end{array}$ & $\begin{array}{l}\text { Caso 1: Tratamento com } \\
\text { imunoglobulina humana intravenosa } \\
\text { (dose de } 400 \mathrm{mg} / \mathrm{kg} / \mathrm{dia} \text { por } 5 \text { dias), } \\
\text { com melhora significativa. } \\
\text { Caso 2: tratado com aciclovir sem } \\
\text { melhora clínica significativa. } \\
\text { Tratamento com i.v. imunoglobulina } \\
\text { (IVlg) (na dose de } 400 \mathrm{mg} / \mathrm{kg} / \text { dia por } \\
5 \text { dias) foi iniciada com melhora } \\
\text { neurológica. }\end{array}$ \\
\hline $\begin{array}{l}\text { CARDONA- } \\
\text { CORREA SE, et } \\
\text { al., } 2017 .\end{array}$ & $\begin{array}{l}\text { Reporte de caso de transmisión } \\
\text { vertical de la infección por virus } \\
\text { chikungunya }\end{array}$ & $\begin{array}{l}\text { Febre, um exantema de localização central e icterícia } \\
\text { de } 1 \\
\text { dia da evolução. }\end{array}$ & $\begin{array}{l}\text { Antibioticoterapia com ampicilina } \\
\text { durante } 4 \text { dias. }\end{array}$ \\
\hline $\begin{array}{l}\text { ALY MM, et al., } \\
2017 .\end{array}$ & $\begin{array}{l}\text { Severe Chikungunya infection in } \\
\text { Northern Mozambique: a case report }\end{array}$ & $\begin{array}{l}\text { Febre, calafrios, } \\
\text { mal-estar geral, fraqueza e prostração, sem cefaleia, } \\
\text { artralgia ou mialgia. Desenvolvimento de cefaléia, } \\
\text { tontura, poliartralgia simétrica e melena. }\end{array}$ & $\begin{array}{l}\text { O paciente foi tratado com } \\
\text { antiácidos e antibióticos. } \\
\text { Antibióticos: ceftriaxona, ciprofloxacina } \\
\text { e ampicilina. }\end{array}$ \\
\hline $\begin{array}{l}\text { COSTA ALFA, et } \\
\text { al., } 2017 .\end{array}$ & $\begin{array}{l}\text { Third Cranial Nerve Palsy after } \\
\text { a Chikungunya Virus Infection }\end{array}$ & $\begin{array}{l}\text { Febre, dor de cabeça e poliartralgia. Depois de um mês, } \\
\text { todos os sintomas desapareceram } \\
\text { mas a paciente percebeu um súbito aparecimento de } \\
\text { desalinhamento ocular, } \\
\text { diplopia binocular e ptose palpebral bilateral. }\end{array}$ & Pulsoterapia com corticoide. \\
\hline
\end{tabular}




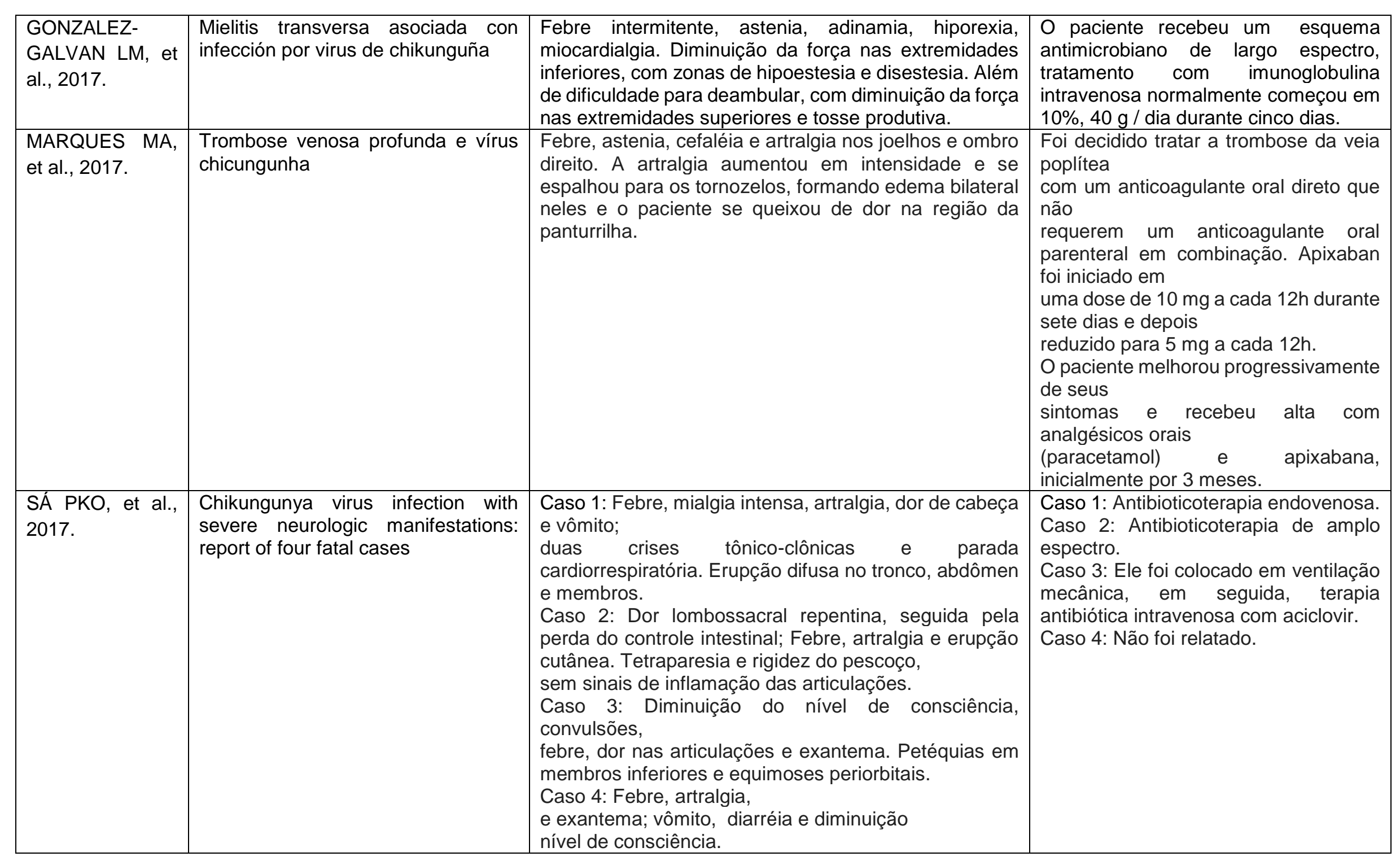




\begin{tabular}{|c|c|c|c|}
\hline $\begin{array}{l}\text { BASTOS MLA, et } \\
\text { al., } 2018 .\end{array}$ & $\begin{array}{l}\text { Thrombotic thrombocytopenic } \\
\text { purpura associated with dengue and } \\
\text { chikungunya virus coinfection: case } \\
\text { report during an epidemic period }\end{array}$ & $\begin{array}{l}\text { Cefaleia com vômitos, associada à confusão mental e, } \\
\text { posteriormente, afasia motora e hemiplegia à direita. }\end{array}$ & $\begin{array}{l}\text { Iniciou-se corticoterapia oral com } \\
\text { prednisona } 1 \mathrm{mg} / \mathrm{kg} / \mathrm{dia} \text {; } \\
\text { Plasmaférese e pulsoterapia com } \\
\text { metilprednisolona foram iniciadas } \\
\text { devido à hipótese de TTP. A } \\
\text { plasmaférese foi mantida até que as } \\
\text { contagens plaquetas } \\
\text { permanecessem acima de } 150.000 \text { por } \\
\text { três dias consecutivos. A remissão } \\
\text { completa dos sinais neurológicos } \\
\text { ocorreu após a primeira plasmaférese. }\end{array}$ \\
\hline $\begin{array}{l}\text { GIACOMIN NT, } \\
\text { et al., 2018. }\end{array}$ & $\begin{array}{l}\text { Neurite óptica secundária a infecção } \\
\text { pelo Chikungunya Vírus }\end{array}$ & $\begin{array}{l}\text { Dor, baixa acuidade visual no olho direito, febre e } \\
\text { poliartralgia simétrica; Fundoscopia com edema no } \\
\text { disco no olho direito; Ressonância magnética da órbita } \\
\text { mostrou nervo óptico direito com calibre aumentado e } \\
\text { realce difuso acentuado, denotando um processo } \\
\text { inflamatório. }\end{array}$ & $\begin{array}{l}\text { Metilprednisolona } 1,5 \mathrm{mg} / \text { dia por } 3 \\
\text { dias; albendazol } 400 \mathrm{mg} / \text { dia por } 3 \text { dias } \\
\text { e prednisona } 1 \mathrm{mg} / \mathrm{kg} / \text { dia por } 7 \text { dias. }\end{array}$ \\
\hline $\begin{array}{l}\text { GUNTURIZ ML, } \\
\text { et al., } 2018 .\end{array}$ & $\begin{array}{l}\text { Toxoplasmosis cerebral congénita e } \\
\text { infección por el virus del Zika y del } \\
\text { chikunguña: reporte de un caso }\end{array}$ & $\begin{array}{l}\text { Apresentou sintomatologia da infecção por ZIKV. } \\
\text { Edema cerebral, vasculite lenticulo-tálamo-triatal, } \\
\text { hiperdensidades na substância branca e nos } \\
\text { hemisférios cerebrais, encefalopatia e lesões dispersas } \\
\text { na substância branca com áreas de hemorragia } \\
\text { intraparenquimatosa foram observadas. }\end{array}$ & $\begin{array}{l}\text { Dadas as anomalias cerebrais fetais, a } \\
\text { mãe solicitou a interrupção voluntária } \\
\text { da gravidez (causada por } \\
\text { toxoplasmose cerebral congênita). }\end{array}$ \\
\hline $\begin{array}{l}\text { ELFERT KA, et } \\
\text { al., } 2019 .\end{array}$ & $\begin{array}{l}\text { Chikungunya Virus Infection-related } \\
\text { Rhabdomyolysis: A Case Report }\end{array}$ & $\begin{array}{l}\text { Febre, mialgia e artralgia, principalmente nos ombros, } \\
\text { quadris e mãos. Diarréia e urina de cor escura. Tosse } \\
\text { produtiva e vermelhidão ocular. Pressão arterial era de } \\
90 / 40 \text { mmHg. Havia injeção conjuntival e sensibilidade } \\
\text { muscular nos ombros e músculos da coxa. }\end{array}$ & $\begin{array}{l}\text { O paciente recebeu tratamento de } \\
\text { suporte. Durante a internação, os } \\
\text { sintomas melhoraram e as } \\
\text { anormalidades } \\
\text { começaram a melhorar. laboratoriais }\end{array}$ \\
\hline
\end{tabular}

Fonte: CARDOSO ACA, et al. 2019 
Os relatos encontrados sobre a associação entre CHIKV e a trombose venosa profunda (TVP) e/ou a embolia pulmonar (EP) não contam com referência alguma na literatura que a comprove. Mesmo assim, devese ficar atento com o desenvolvimento nos casos mais graves da febre de CHIKV. Isso, porque o processo inflamatório agudo e crônico desenvolve fatores desencadeantes para o desenvolvimento de TVP e/ou EP em paciente portador, ou não, de trombofilia. Esses fatores são: a imobilização dos pacientes pela poliartralgia intensa e pela astenia e à desidratação secundária à febre alta (MARQUES CDL, et al. 2017).

Casos graves da infecção pelo CHIKV também foram capazes de causar rabdomiólise em determinados pacientes. O quadro clínico de miosite juntamente com a tríade sintomática de febre, mialgia e urina escurecida, são favoráveis para o diagnóstico de rabdomiólise. Pacientes com esse quadro foram submetidos a biópsias imunohistológicas onde foram encontrados antígenos virais exclusivamente dentro de células progenitoras do músculo esquelético (designadas como células satélites) e não em fibras musculares. As células satélites são células precursoras miogênicas que persistem em músculo pós-natal e adulto. Também foram realizados estudos in vitro, os quais mostraram que o Chikungunya virus tem a capacidade de se replicar dentro de células satélites humanas com efeito citopático, enquanto não está crescendo dentro dos miotubos (ELFERT KA, et al. 2019).

De acordo com os achados do quadro 1, os tratamentos mais utilizados foram a base de corticosteroides, antibioticoterapia e imunoglobulina. Todavia, apenas um dos estudos expostos na tabela utilizaram, concomitantemente, dois desses tipos de medicamentos, sendo eles o antibiótico e a imunoglobulina. E nenhum deles realizaram o tratamento com o uso de todos eles (Quadro 1).

\section{CONCLUSÃO}

Os agravos causados pela infecção do Chikungunya virus (CHIKV) possuem um conjunto considerável e de variados acometimentos. O seu alcance amplo e imprevisível, determina uma das maiores preocupações em frente às sequelas causadas por eles. Isso se deve tanto aos agravos causados pela infeção como, também, a descompensação de comorbidades pré-existentes nas pessoas acometidas pelo vírus. Além disso, a facilidade de disseminação da doença e a inexistência de uma vacina contra o vírus são fatores que dificultam, significativamente, sua prevenção. A variedade de condutas encontradas nos estudos do quadro 1, com poucos tratamentos semelhantes, mostra a falta de evidências na literatura que apontem para um tratamento específico da febre da Chikungunya. Devido a isso, o número de pessoas acometidas pelo CHIKV tem aumentado, causando não somente danos fisiopatológicos, mas, também, gerando impactos econômicos devido à alta capacidade de incapacitação da doença. De certa forma, mesmo que ainda insuficientes e/ou inconclusivos, os trabalhos voltados para esta infecção enriquecem o acervo literário e contribuem para o seu melhor manuseio, assim como, servem de apoio para novas pesquisas.

\section{REFERÊNCIAS}

1. ALY MM, ALI S, MUIANGA AF et al. "Severe Chikungunya infection in Northern Mozambique: a case report." BMC research notes vol. 10,1 88. 8 Feb. 2017.

2. Bank AM, Batra A, Colorado RA, et al. Myeloradiculopathy associated with chikungunya virus infection. J Neurovirol. 2016 Feb;22(1):125-8.

3. BASTOS, MLA, ARAÚJO RMO, OLIVEIRA DS, et al. Thrombotic thrombocytopenic purpura associated with dengue and chikungunya virus coinfection: case report during an epidemic period.Rev. Inst. Med. trop. S. Paulo, São Paulo, v. 60, e48, 2018

4. BENZEKRI, R, HAGE R, MERLE H. "Third Cranial Nerve Palsy in the Setting of Chikungunya Virus Infection." The American journal of tropical medicine and hygiene vol. 95,1 (2016).

5. CARDONA-CORREA SE, CASTANO-JARAMILLO LM, QUEVEDO-VELEZ A. Reporte de caso de transmisión vertical de la infección por virus chikungunya.Rev. chil. pediatr., Santiago, v. 88, n. 2, p. 285-288, abr. 2017

6. COSTA ALFA, MARTINS TGDS, MARTINS DGSM. Third Cranial Nerve Palsy after a Chikungunya Virus Infection. Strabismus. 2017 Dec;25(4):172-175

7. CUNHA RV, TRINTA, KS. Vírus Chikungunya: aspectos clínico e tratamento - Uma revisão, Mem. Inst. Oswaldo Cruz vol.112 no.8 Rio de Janeiro Aug. 2017.

8. DONALISIOL MR, FREITAS ARR. Chikungunya no Brasil: um desafio emergente, Revista Brasileira de Epidemiologia, Campinas, 2015. 
9. ELFERT KA, ABDELWAHED M, CHI G. "Chikungunya Virus Infection-related Rhabdomyolysis: A Case Report." Cureus vol. 11,2 e4036. 8 Feb. 2019.

10. ESTOFOLETE CF, MOTA MTO, VEDOVELLO D et al. Mayaro fever in an HIV-infected patient suspected of having Chikungunya fever. Rev. Soc. Bras. Med. Trop., Uberaba, v. 49, n. 5, p. 648-652, Oct. 2016.

11. GIACOMIN NT, DEMACHKI NT, GIACOMIN-JUNIOR PJ et al. Optic neuritis secondary to chikungunya virus infection.Rev. bras.oftalmol., Rio de Janeiro, v. 77, n. 4, p. 222-224, Aug. 2018.

12. GONZALEZ-GALVAN LM, ARREDONDO-RUIZ P, CHAC-LEZAMA G et al. Mielitis transversa asociada con infección por virus de chikunguña. Med. interna Méx., Ciudad de México, v. 33, n. 1, p. 109-115, feb. 2017.

13. HONÓRIO NA, CÂMARA DCP, CALVET GA et al. Cad. Saúde Pública, Chikungunya: uma arbovirose em estabelecimento e expansão no Brasil, Rio de Janeiro, 2015.

14. LEAO JC, MARQUES C, DUARTE U et al. Chikungunya Fever: General and oral healthcare implications, Prof Scully Memorial Issue, 20 August 2017.

15. LIN J, CHEN RWS, HAZAN A et al. Chikungunya Virus Infection Manifesting as Intermediate Uveitis. Ocul Immunol Inflamm. 2018;26(5):680-682.

16. LOPES N, NOZAWA C, LINHARES REC. Características gerais e epidemiologia dos arbovírus emergentes no Brasil. Rev PanAmaz Saude, Ananindeua, v. 5, n. 3, p. 55-64, set. 2014

17. LUCENA-SILVA N, ASSUNÇÃO MELSM, RAMOS FAP, et al. Encephalitis associated with inappropriate antidiuretic hormone secretion due to chikungunya infection in Recife, State of Pernambuco, Brazil.Rev. Soc. Bras. Med. Trop., Uberaba, v. 50, n. 3, p. 417-422, June 2017.

18. MARQUES CDL, DUARTE ALBP, RANZOLIN A, et al. Recomendações da Sociedade Brasileira de Reumatologia para diagnóstico e tratamento da febre chikungunya. Parte 1 - Diagnóstico e situações especiais, Rev. Bras. Reumatol. vol.57 supl.2 São Paulo 2017.

19. MARQUES CDL, DUARTE ALBP, RANZOLIN A, et al Recomendações da Sociedade Brasileira de Reumatologia para diagnóstico e tratamento da febre chikungunya. Parte 2 - Tratamento, Rev. Bras. Reumatol. vol.57 supl.2 São Paulo 2017.

20. MARQUES MA, SÁ FPA, LUPI O et al. Trombose venosa profunda e vírus chicungunha, J. vasc. bras. vol.16 no.1 Porto Alegre Jan./Mar. 2017

21. MARTINS HA, BERNARDINO SN, SANTOS CC et al. "Chikungunya and Myositis: A Case Report in Brazil." Journal of clinical and diagnostic research : JCDR vol. 10,12 (2016).

22. MAHENDRADAS P, AVADHANI K, SHETTY R. "Chikungunya and the eye: a review." Journal of ophthalmic inflammation and infection vol. 3,1 35. 11 Feb. 2013.

23. MEHTA R, GERARDIN P, BRITO CAA et al. "The neurological complications of chikungunya virus: A systematic review." Reviews in medical virology vol. 28,3 (2018): e1978. doi:10.1002/rmv.1978.

24. PINHEIRO TJ, GUIMARÃES LF, SILVA MTT et al. Neurological manifestations of Chikungunya and Zika infections. Arq. NeuroPsiquiatr., São Paulo, v. 74, n. 11, p. 937-943, Nov. 2016

25. RAINEY SM, SHAH P, KOHL A et al. Understanding the Wolbachiamediated inhibition of arboviruses in mosquitoes: progress and challenges, Journal of General Virology 95: 517-530, 01 March 2014.

26. SÁ PKO, NUNES MM, LEITE IR et al. Chikungunya virus infection with severe neurologic manifestations: report of four fatal cases, Rev. Soc. Bras. Med. Trop. vol.50 no.2 Uberaba Mar./Apr. 2017.

27. SCOTT SSO, BRAGA-NETO P, PEREIRA LP et al. Immunoglobulin-responsive Chikungunya encephalitis: two case reports. J Neurovirol. 2017 Aug;23(4):625-631.

28. TORCELLI RE. Complicaciones neurológicas del virus chikunguya y dengue, Pediátr Panamá 2017; 46 (2): 46-51.

29. VARGAS CM. Fiebre de Chikungunya: Una nueva enfermedad emergente de gran impacto en la salud pública, Rev Med Hered vol.26 no.1 Lima ene. 2015. 